\title{
Variação linguística na Língua Brasileira de Sinais utilizada em Maceió/Alagoas
}

\author{
Priscila Rufino da Silva \\ Liliane Correia Toscano de Brito Dizeu ${ }^{1}$
}

\section{Resumo}

Nesta pesquisa objetivou-se descrever a ocorrência de variação linguistica na Lingua de sinais usada em Maceió/AL. Para o desenvolvimento deste estudo, utilizaram-se os pressupostos da Sociolinguística Variacionista (LABOV, 2008 [1972]) cujo principal objetivo é demonstrar que o aparente caos linguístico pode ser sistematizado e descrito, bem como a variação linguística pode estar ocorrendo por meio da influência de fatores linguísticos e sociais. O corpus da presente pesquisa foi constituído por meio da gravação dos sinais de 50 figuras realizados por 23 informantes estratificados de acordo com os seguintes fatores extralinguisticos: sexo, idade e escolaridade. De acordo com os resultados desse corpus, pode-se dizer que a Lingua Brasileira de Sinais utilizada em Maceió/AL apresenta variações condicionadas por fatores extralinguísticos e internos ao seu sistema, por conseguinte, os grupos de $1^{a}$ a $4^{a}$ série, de 33 a 41 anos de idade e do sexo feminino apresentaram mais variações nos parâmetros analisados (configuração manual, movimento e ponto de articulação).

Palavras-chave: Linguagem de sinais. Sociolinguística. Variação

\footnotetext{
${ }^{1}$ Professoras da Universidade Estadual de Ciências da Saúde de Alagoas.
} 


\section{Introdução}

A Sociolinguística variacionista (LABOV, 2008[1972]), uma das subáreas da Linguística, estuda a língua em uso no seio das comunidades de fala, sua investigação correlaciona aspectos linguísticos a aspectos sociais com o intuito de sistematizar o aparente caos da fala cotidiana. Essa teoria é um espaço de investigação interdisciplinar, que atua nas fronteiras entre língua e sociedade, verificando, principalmente, os empregos concretos da língua (MOLLICA, 1994).

A variação é o principal objeto de estudo da sociolinguística; ela é vista como princípio geral e universal das línguas, passível de ser descrita e analisada. Mollica (1994) destaca que existem dois tipos de eixos em que as variações existem: o eixo diatópico e o eixo diastrático. No primeiro, as alternâncias se expressam regionalmente, sendo considerados os limites físicogeográficos; no segundo, a manifestação ocorre pelos diferentes estratos sociais; nesse caso, são consideradas as fronteiras sociais.

A teoria da variação questiona a concepção de língua defendida pelo estruturalismo e gerativismo. Essas correntes viam a língua como um sistema homogêneo, uniforme, estático e possível de ser estudado sem que se levassem em consideração os usos linguísticos reais em situações cotidianas de comunicação. Na Sociolinguística, não obstante, esse ponto passa a ser considerado fundamental, principalmente, o estudo dentro do contexto social (HORA, 2004).

Os condicionantes que promovem o surgimento de formas variantes são em geral em grande número, atuam simultaneamente e surgem de dentro ou fora dos sistemas linguísticos (MOLLICA, 1994). Nessa teoria a língua é um instrumento de comunicação utilizado por falantes da comunidade, num sistema de associação aceito entre formas arbitrárias e seus significados. Seu objetivo é explicar o processo de mudança linguística baseada em diversos fatores linguísticos e/ou variáveis internas da língua; e sociais, variáveis essas relacionadas ao falante (sexo, idade, grau de escolaridade, etc.), segundo Hora (2004).

As mudanças da fala ocorrem pela especificidade do tempo e lugar (LABOV, 2008[1972]). Dessa forma, toda variação ou mudança linguística somente existe quando a língua é usada em um meio social.

Revista Leitura v. 1, no 58 - Maceió - Jan./Jun. 2017 - ISSN 2317-9945

Línguas de Sinais: abordagens teóricas e aplicadas, p. 47-67 
Em uma pesquisa realizada na Nova Zelândia (MCKEE; MCKEE, 2006), foi observada a ocorrência de variações linguísticas no léxico da Língua de Sinais da Nova Zelândia, sendo essas possivelmente decorrentes do modelo educacional, os grupos de sujeitos surdos mais velhos usuários desta língua de sinais apresentaram diferenças no uso da língua comparado a um grupo mais jovem. O grupo de surdos mais velhos teve uma experiência educacional a partir de um modelo voltado para a oralidade, enquanto que o grupo de surdos mais jovens vivenciou um período educacional em que a língua de sinais foi introduzida nas escolas e a comunidade surda da Nova Zelândia passava por um processo de mudança de língua.

Por ser uma língua de modalidade gesto-visual, a Língua Brasileira de Sinais (Libras) faz uso de movimentos gestuais e expressões faciais que são percebidos pela visão (PEREIRA, 2000). Quanto à estrutura, tanto as línguas de sinais quanto as línguas faladas apresentam as mesmas propriedades abstratas da linguagem, mas se opõem fortemente na sua forma na superfície. Os estudos de Stokoe, em 1960, mostraram que os sinais não são somente imagens, mas símbolos abstratos, possuindo uma complexa estrutura interior. Stokoe foi o pioneiro na investigação para buscar a estrutura, analisar os sinais e segmentá-los, e a pesquisar suas partes constituintes (QUADROS; KARNOPP, 2004).

Stokoe primeiramente comprovou que cada sinal era constituído por pelo menos três partes independentes (em analogia com os fonemas da fala): o ponto de articulação (PA), a configuração das mãos (CM) e o movimento $(\mathrm{M})$, sendo que cada uma dessas partes apresenta um número limitado de combinações (QUADROS; KARNOPP, 2004).

Os articuladores primários, nas línguas de sinais, são as mãos, que se movimentam no espaço em frente ao corpo e articulam sinais em determinados pontos de articulação. Não obstante, um sinal pode ser articulado com uma ou duas mãos (QUADROS; KARNOPP, 2004). 

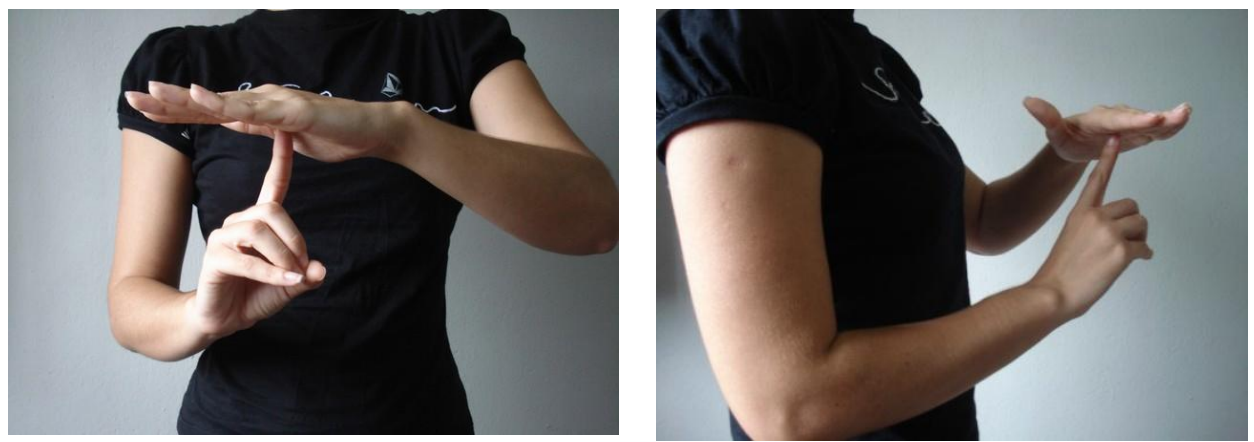

Figura 1: Sinal de helicóptero.

Na figura 1, a mão esquerda está aberta, configuração manual [5] e a mão direita está em formato da letra D do alfabeto manual, isto é, configuração manual [Gd]. Por conseguinte, o ponto de articulação é o espaço em frente ao corpo ou uma região do próprio corpo, onde os sinais são articulados. Os sinais articulados são de dois tipos: os que se articulam no espaço neutro diante do corpo e os que se aproximam de uma determinada região do corpo, tais como: cabeça, mão, cintura e os ombros (FERREIRA BRITO, 1995).
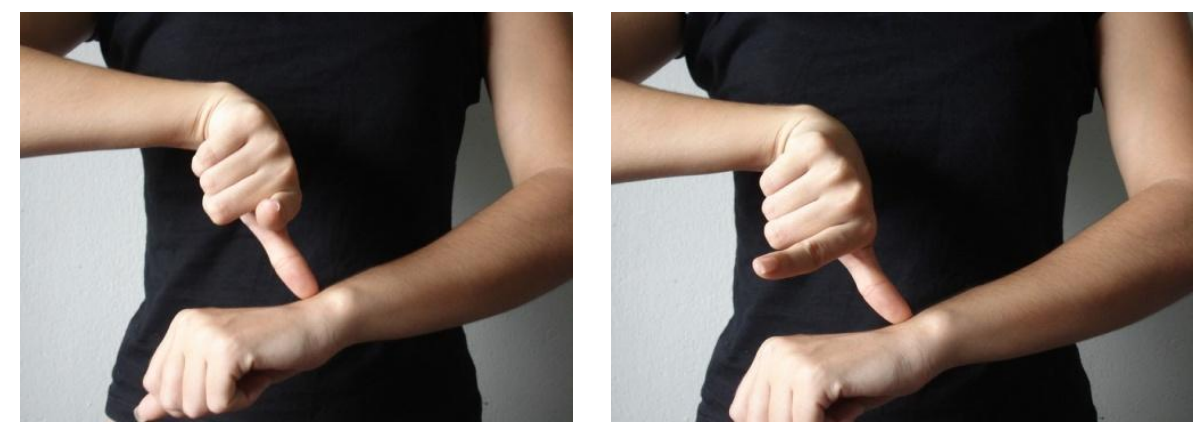

Figura 2: Sinal de relógio.

$\mathrm{Na}$ figura 2, a mão direita está tocando o pulso esquerdo com o polegar e se movimentando de forma unidirecional para a direita. O movimento pode envolver uma vasta rede de formas e direções, desde movimentos internos da mão, movimentos do pulso e movimentos direcionais no espaço (QUADROS; KARNOPP, 2004). 

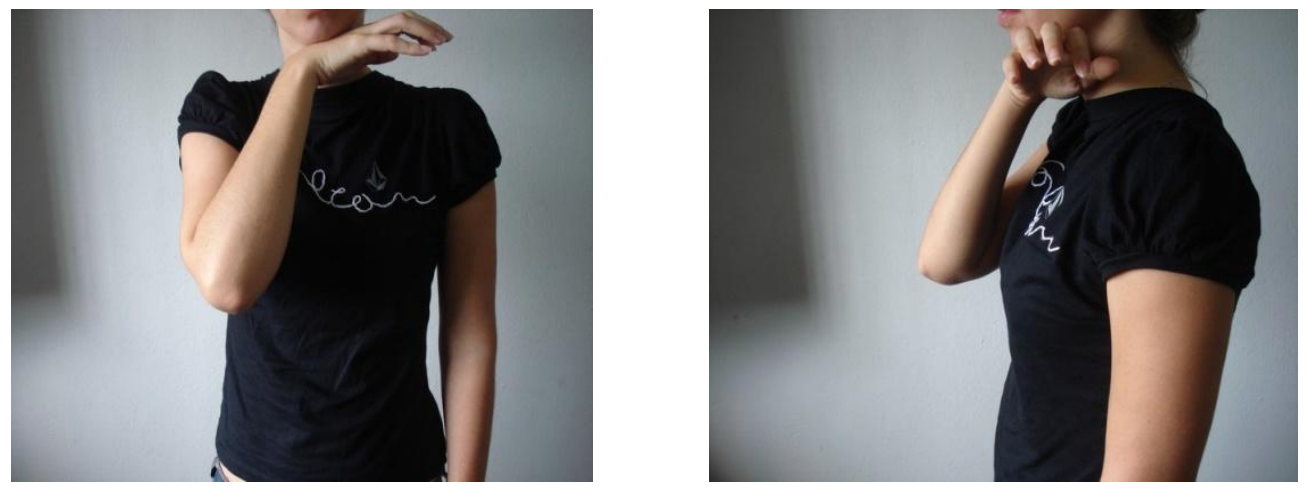

Figura 3: Sinal de leão.

Na figura 3, o sinal está sendo articulado na região do queixo. Diferente das línguas orais, nas quais os fonemas são produzidos pela passagem de ar pela laringe, nariz e boca; nas línguas de sinais, a estrutura fonológica se organiza pelos parâmetros visuais (FERREIRA BRITO, 1995).

Durante muito tempo, as línguas de sinais foram consideradas apenas como gestos, incapazes de expressar conceitos abstratos. Atualmente, ainda há muito preconceito e desconhecimento sobre seu real funcionamento.

Todos os sinais que fazem parte do léxico utilizam parâmetros considerados gramaticais e aceitos na língua de sinais; isso vem confirmar que a Libras é um sistema linguístico que se constrói a partir de regras, o que a distancia dos gestos naturais e das mímicas, que não possuem restrições quanto à articulação (FERREIRA BRITO, 1995).

As línguas de sinais só foram reconhecidas como língua quando surgiu um sistema de notação que pudesse representar a estrutura de seus sinais. Os primeiros estudos que mencionam as línguas de sinais datam da década de 1960, com os trabalhos sobre a Língua de Sinais Americana (ASL) realizados por Stokoe (HOITING; SLOBIN, 2002). Desta maneira, as pesquisas sobre as línguas de sinais são muito recentes se comparadas às línguas faladas. Além disso, a maioria dessas línguas de sinais ainda não está totalmente descrita em seus níveis fonológico, morfológico e sintático e carece de maior investigação. Com relação à Libras, as pesquisas linguísticas ainda são escassas, e há necessidade de mais trabalhos na área. 
Quanto à educação dos surdos, as decisões interferiram no processo histórico das comunidades surdas, por não poderem usar a língua de sinais. Isso provocou profundas mudanças em suas vidas. A autora refere ainda que os surdos passaram a ter um papel muito importante no processo educacional, no momento em que sua língua passa a ser respeitada como uma língua própria de sua comunidade (QUADROS, 1997).

De 1880 a meados de 1950, o uso da língua de sinais nas escolas era proibido mundialmente; apesar disso, essa língua sobreviveu, pois nunca deixou de ser usada pelos surdos. Após uma época de resultados educacionais insatisfatórios dos alunos surdos, em 1960, foi retomado o estudo sobre a língua de sinais por Stokoe. Nesse momento, ela já não era mais abolida por todos e os surdos puderam usar livremente sua língua.

No entanto, apenas a partir 1980 é que essa língua foi retomada na educação de surdos, o que se tornou possível devido à Proposta de Educação Bilíngue para Surdos (MOURA et al, 1997). Nesta época nos países Nórdicos, principalmente na Suécia e Dinamarca, teve início a visão bilíngue de educação para surdos. Marcando, dessa forma, uma importante mudança para a educação e a vida desses sujeitos (JOKINEN, 1999).

No estado de Alagoas, foi decretada a Lei no 6060 em 15 de Setembro de 1998, a qual reconhece e implanta a Libras na rede pública de ensino para surdos. Nacionalmente, em 2002 ocorreu a oficialização da Libras como a língua dos surdos brasileiros, com a Lei n ${ }^{\circ} 10.436$, de 24 de abril de 2002, fato esse que abriu novos caminhos para a comunidade surda (MINISTÉRIO DA EDUCAÇÃO, 2002).

Algumas escolas regulares públicas da cidade de Maceió, no Estado de Alagoas, disponibilizam intérpretes em sala de aula, viabilizando o contato dos alunos surdos com seus pares e promovendo a aquisição da língua de sinais e a constituição da identidade do ser surdo. Isto é possível devido à implantação de um projeto elaborado para atender às suas necessidades, respeitando, assim, os seus direitos como cidadãos.

As línguas de sinais desenvolvem-se na comunidade surda; os surdos de uma determinada região encontram-se e comunicam-se por intermédio da língua de sinais, da mesma maneira que qualquer grupo sócio-cultural que utiliza a língua falada. Essas línguas não

Revista Leitura v. 1, no 58 - Maceió - Jan./Jun. 2017 - ISSN 2317-9945

Línguas de Sinais: abordagens teóricas e aplicadas, p. 47-67 
se derivaram das línguas orais, mas da necessidade do surdo de estabelecer uma modalidade linguística que permita sua comunicação (DIZEU, 2006).

A Fonoaudiologia e a Linguística juntamente com as demais áreas afins devem aprofundar seus estudos com o propósito de permitir aos sujeitos surdos o desenvolvimento linguístico, educacional, social, emocional e cultural. Para tanto, é importante a realização de pesquisas linguísticas que venham a contribuir com o conhecimento, com o intuito de compreender melhor essa língua, além de colaborar para que os profissionais possam traçar melhor um plano de trabalho, conhecendo nuances das variações dessa língua (DIZEU, 2006).

A partir do estudo realizado com a Língua de Sinais da Nova Zelândia surgiu o interesse de verificar se na Língua Brasileira de Sinais é possível ocorrer variações linguísticas, tendo em vista o processo educacional desenvolvido na cidade de Maceió decorrente da mudança político e social sofrida pela Libras.

A partir dos resultados alcançados nesta pesquisa, será possível mostrar a relevância de trabalhos que abordem essa temática variacionista, com vistas ao aprimoramento da situação educacional e terapêutica do surdo alagoano, promovendo, desta feita, um olhar diferenciado sobre os aspectos que merecem ser descritos na Libras.

\section{Metodologia}

Para a realização desta pesquisa foram selecionados, a partir do estudo de Mckee e Mckee (2006) e baseados na realidade local ${ }^{2} 50$ itens lexicais de cinco categorias semânticas, como: alimento, animal, cor, meio de transporte e vestuário (Anexo 1), estando as figuras apresentadas em folha A4, com imagens reais e coloridas. O léxico selecionado foi adaptado de acordo com a realidade dos sujeitos, utilizando figuras comuns na região, por não haver um modelo de pesquisa nacional nem com a língua portuguesa e nem com a Libras.

A metodologia usada na constituição do corpus foi a utilizada pelos trabalhos de sociolinguística a partir da perspectiva variacionista (HORA, 2004). A identificação de

${ }^{2}$ Como exemplo, podemos citar os itens caju e carroça, que fazem parte da cultura local.

Revista Leitura v. 1, no 58 - Maceió - Jan./Jun. 2017 - ISSN 2317-9945

Línguas de Sinais: abordagens teóricas e aplicadas, p. 47-67 
fenômenos variáveis pressupõe que, para os membros de uma mesma comunidade de fala, existam pelo menos duas possibilidades de representação superficial para uma determinada categoria linguística (GOMES; SOUZA, 2004). Como também, a escolha entre as formas não se dá de maneira aleatória ou livre, mas está estreitamente correlacionada a variáveis linguísticas e extralinguísticas, como veremos adiante (sexo, idade e escolaridade). Desta feita, na Libras, as variações são as modificações que surgem nos sinais dos informantes, como é possível verificar nos exemplos a seguir:

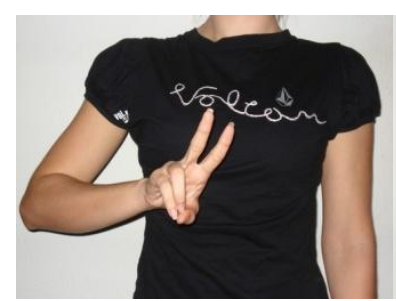

Figura 4: número 11a.

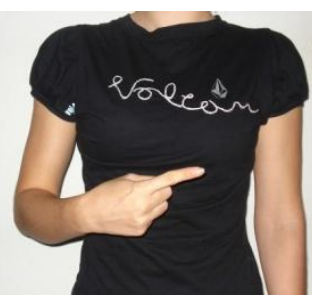

Figura 5: número $11 b$.

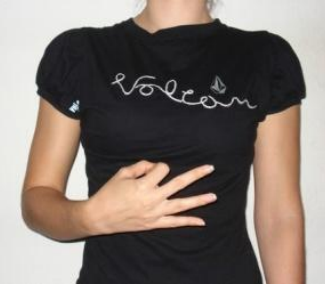

Figura 6: número 3a.

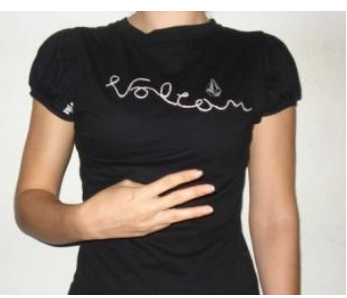

Figura 7: número 3b.

Nas figuras 4 e 5, é sinalizado o número 11 em Língua de Sinais da Nova Zelândia (NZSL), elas apresentam-se diferentes quanto à configuração manual, movimento e orientação da mão, ou seja, é verificada a variação do sinal do número 11 no aspecto fonológico. Nas figuras 6 e 7, a variação fonológica do sinal do número três é observada pela diferença na configuração manual.

A presente pesquisa contou com a participação de 23 sujeitos, sendo feita uma estratificação de acordo com as variáveis sexo, idade e escolaridade:

Sexo:

Masculino: 12 informantes

Feminino: 11 informantes

Faixa etária:

$\begin{array}{ll}15 \text { a } 23 & 08 \text { informantes } \\ 24 \text { a } 32 & 08 \text { informantes } \\ 33 \text { a } 41 & 07 \text { informantes }\end{array}$

Revista Leitura v. 1, no 58 - Maceió - Jan./Jun. 2017 - ISSN 2317-9945

Línguas de Sinais: abordagens teóricas e aplicadas, p. 47-67 
Escolaridade:
$1^{\circ}$ ao $5^{\circ}$ ano
06 informantes
$6^{\circ}$ ao $9^{\circ}$ ano
06 informantes
Ensino médio
06 informantes
Ensino superior
05 informantes

Em princípio, foi estipulado que o número de sujeitos participantes da pesquisa seria de 24 , contudo, não foi encontrado um sujeito do sexo feminino com faixa etária entre 33 a 41 anos que estivesse cursando ou houvesse concluído o ensino superior na cidade de Maceió. Por conseguinte, a pesquisa contou com a participação de 23 sujeitos.

A coleta de dados teve início após aprovação do Comitê de Ética e Pesquisa da Universidade Estadual de Ciências da Saúde de Alagoas (UNCISAL) ${ }^{3}$, sendo realizada no período de quatro meses, em um encontro, previamente marcado, com cada participante, conforme a disponibilidade de cada um. Em cada encontro, antes de iniciar a coleta, a pesquisadora interpretou e explicou em Libras o texto do Termo de Consentimento Livre e Esclarecido (TCLE) para os participantes da pesquisa, após a leitura e concordância em participar como sujeito da pesquisa, os informantes assinaram o TCLE. Em seguida, a pesquisadora aplicou uma ficha social para verificar os critérios de inclusão e posterior classificação, a partir dos aspectos extralinguísticos (sexo, idade e escolaridade). Os dados foram coletados a partir da apresentação das figuras (uma por uma) e da respectiva demonstração do sinal. A nova figura era apresentada somente após a sinalização da anterior.

Todos os encontros foram filmados, visando viabilizar a análise dos dados. Cada filmagem durou aproximadamente 5 minutos, totalizando 115 minutos.

Foram consideradas como variações as modificações que surgiram nos sinais dos informantes em relação aos aspectos fonológicos, em um ou mais parâmetros ${ }^{4}$, visto que, qualquer modificação do movimento, da configuração das mãos ou do ponto de articulação

\footnotetext{
3 A pesquisa "Variação linguística na Língua Brasileira de Sinais utilizada em Maceió, Alagoas" foi aprovada pelo Comitê de ética e pesquisa da UNCISAL, segundo protocolo de número 786.

4 Serão utilizados os parâmetros primários da LIBRAS descritos por Ferreira Brito e Langevin (1995) e Ferreira Brito (1990) apud QUADROS; KARNOPP, 2004).
}

Revista Leitura v. 1, no 58 - Maceió - Jan./Jun. 2017 - ISSN 2317-9945

Línguas de Sinais: abordagens teóricas e aplicadas, p. 47-67 
(Anexo 2) pode alterar o significado do sinal apresentado. Como parâmetro de análise, foi utilizado o "Dicionário Enciclopédico Trilíngue da Língua de Sinais Brasileira”, volumes I e II (CAPOVILLA; RAPHAEL, 2001), por ser um material teórico construído a partir de dados coletados nas principais capitais brasileiras, podendo-se encontrar especificações quanto aos sinais utilizados em algumas das principais capitais, tal como São Paulo. Como a língua recebe várias interferências regionais, um objeto pode apresentar mais de um sinal dependendo da localização geográfica em que é utilizado.

\section{Resultados}

Os dados analisados encontram-se expostos nas tabelas a seguir, em porcentagens de variações linguísticas referentes aos três parâmetros da Libras: configuração manual, movimento e ponto de articulação, sendo analisados e divididos segundo os aspectos extralinguísticos: sexo, idade e escolaridade.

\begin{tabular}{|l|c|c|c|c|}
\hline & PARÂMETRO I & PARÂMETRO II & PARÂMETRO III & \\
\hline ESCOLARIDADE & $\begin{array}{c}\text { CONFIGURAÇÃO } \\
\text { MANUAL }\end{array}$ & MOVIMENTO & $\begin{array}{c}\text { PONTO DE } \\
\text { ARTICULAÇÃO }\end{array}$ & TOTAL \\
\hline $1^{\circ}$ ao $5^{\circ}$ ano & $57,52 \%$ & $50,75 \%$ & $46,62 \%$ & $51,63 \%$ \\
\hline $6^{\circ}$ ao $9^{\circ}$ ano & $56,27 \%$ & $42,65 \%$ & $40,50 \%$ & $46,47 \%$ \\
\hline Ensino médio & $52,05 \%$ & $40,06 \%$ & $40,41 \%$ & $44,17 \%$ \\
\hline Ensino superior & $46,93 \%$ & $37,55 \%$ & $37,14 \%$ & $40,54 \%$ \\
\hline
\end{tabular}

Tabela 1: Parâmetros primários correlacionados à escolaridade.

\begin{tabular}{|c|c|c|c|c|}
\hline & PARÂMETRO I & PARÂMETRO II & PARÂMETRO III & \\
\hline IDADE & $\begin{array}{c}\text { CONFIGURAÇÃO } \\
\text { MANUAL }\end{array}$ & MOVIMENTO & $\begin{array}{c}\text { PONTO DE } \\
\text { ARTICULAÇÃO }\end{array}$ & TOTAL \\
\hline 15 a 23 anos & $50,13 \%$ & $38,04 \%$ & $37,27 \%$ & $41,81 \%$ \\
\hline 24 a 32 anos & $53,03 \%$ & $43,53 \%$ & $39,31 \%$ & $45,29 \%$ \\
\hline
\end{tabular}

Revista Leitura v. 1, no 58 - Maceió - Jan./Jun. 2017 - ISSN 2317-9945

Línguas de Sinais: abordagens teóricas e aplicadas, p. 47-67 


\begin{tabular}{|l|l|l|l|l|}
\hline 33 a 41 anos & $59,36 \%$ & $47,62 \%$ & $48,25 \%$ & $51,74 \%$ \\
\hline
\end{tabular}

Tabela 2: Parâmetros primários correlacionados à idade.

\begin{tabular}{|l|l|l|l|l|}
\hline & \multicolumn{1}{|c|}{ PARÂMETRO I } & PARÂMETRO II & PARÂMETRO III & \\
\hline SEXO & $\begin{array}{c}\text { CONFIGURAÇÃO } \\
\text { MANUAL }\end{array}$ & MOVIMENTO & $\begin{array}{c}\text { PONTO DE } \\
\text { ARTICULAÇÃO }\end{array}$ & TOTAL \\
\hline Feminino & $54,05 \%$ & $43,63 \%$ & $42,85 \%$ & $46,84 \%$ \\
\hline Masculino & $52,74 \%$ & $41,94 \%$ & $39,64 \%$ & $44,77 \%$ \\
\hline
\end{tabular}

Tabela 3: Parâmetros primários correlacionados ao sexo.

\section{Discussão}

A seguir serão discutidos os dados coletados na pesquisa, na qual verificou-se a ocorrência de variações sociolinguísticas na Língua Brasileira de Sinais em uma comunidade de sinalizadores surdos da cidade de Maceió.

Os resultados mostram que todos os sujeitos da pesquisa apresentaram variações em algum ou nos três parâmetros analisados (configuração manual, movimento e ponto de articulação) em todos os sinais, exceto no sinal de bicicleta. Contudo, ocorreu um maior número de variações linguísticas nos sujeitos com escolaridade de $1^{\circ}$ ao $5^{\circ}$ ano, com idade entre 33 a 41 anos e do sexo feminino.

O conteúdo educacional do aluno surdo não abrange os aspectos culturais da comunidade surda nem a estrutura linguística da Libras, sua primeira língua, o que pode interferir no número de ocorrência de variações entre os usuários desta língua. Apesar de o surdo ter, atualmente, acesso à Libras em um ambiente escolar, não há o ensino formal dessa língua.

Revista Leitura v. 1, no 58 - Maceió - Jan./Jun. 2017 - ISSN 2317-9945

Línguas de Sinais: abordagens teóricas e aplicadas, p. 47-67 
Para exemplificar os dados encontrados serão mostrados alguns sinais realizados pelos informantes e a forma correspondente no "Dicionário enciclopédico ilustrado trilíngue da Língua de Sinais Brasileira". Nos parâmetros analisados foram verificadas as seguintes porcentagens de variações linguísticas com maior significância:

\section{Configuração manual}

Escolaridade $1^{\circ}$ ao $5^{\circ}$ ano: $57,52 \%$

Idade entre 33 a 41 anos: 59,36\%

Sexo feminino: $54,05 \%$

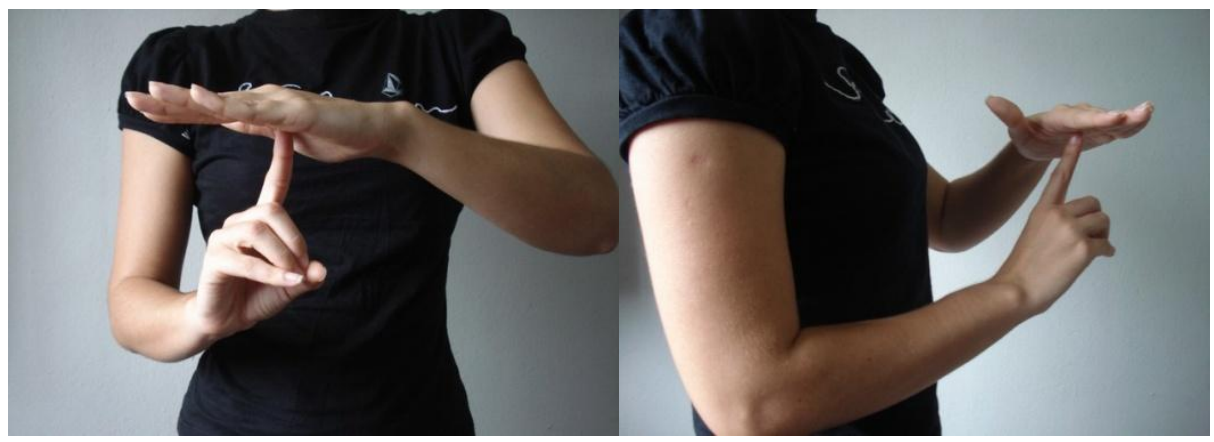

Figura 8: sinal de helicóptero segundo o "Dicionário enciclopédico ilustrado trilíngue da Língua de Sinais Brasileira" (2001).

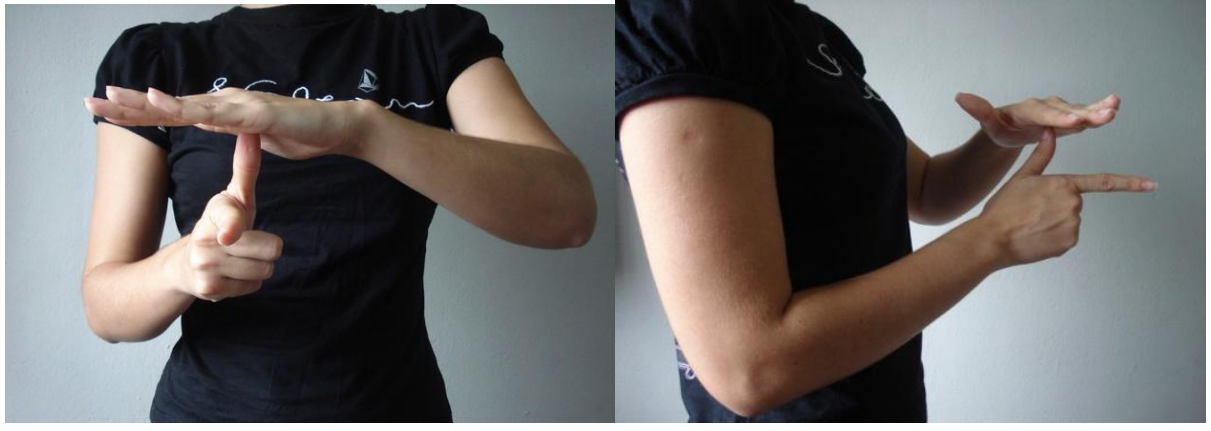

Figura 9: variante do sinal de helicóptero.

Na figura 8, a mão esquerda apresenta-se com a configuração manual [5] e a mão direita com a configuração manual [Gd]. Na figura 9, a mão esquerda também se apresenta com a configuração manual [5], porém a mão direita realiza o sinal com a configuração manual [L]. 
Movimento

Escolaridade $1^{\circ}$ ao $5^{\circ}$ ano: $50,75 \%$

Idade entre 33 a 41 anos: $47,62 \%$

Sexo feminino: $43,63 \%$

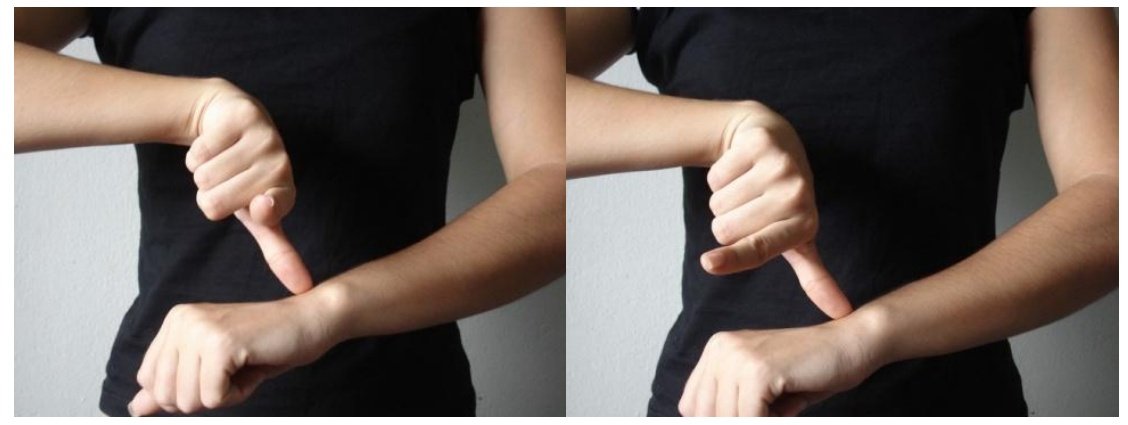

Figura 10: sinal de relógio segundo o "Dicionário enciclopédico ilustrado trilíngue da Língua de Sinais Brasileira" (2001).

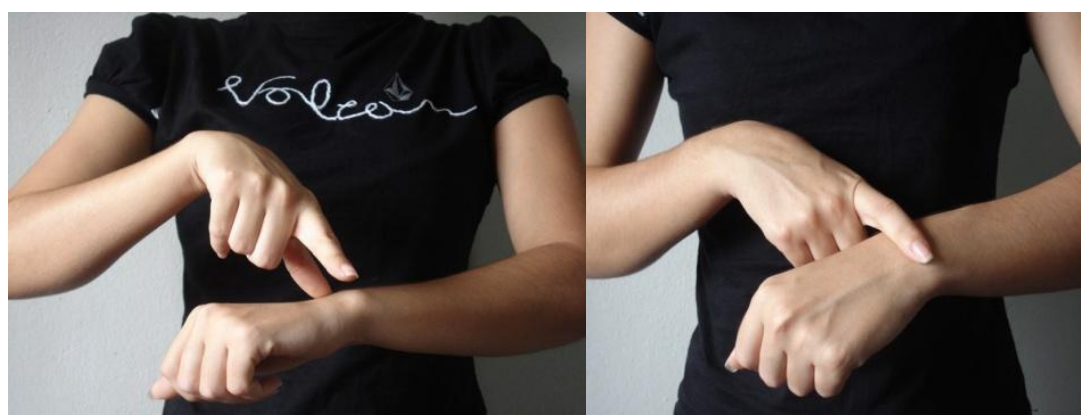

Figura 11: variante do sinal de relógio.

Observa-se na figura 10 o movimento semicircular, de rotação, unidirecional para a direita, diferentemente da variante da figura 11, na qual se verifica o movimento de toque, unidirecional de cima para baixo. 
Ponto de articulação

Escolaridade $1^{\mathrm{a}}$ a $4^{\mathrm{a}}$ série: $46,62 \%$

Idade entre 33 a 41 anos: 48,25\%

Sexo feminino: $42,85 \%$

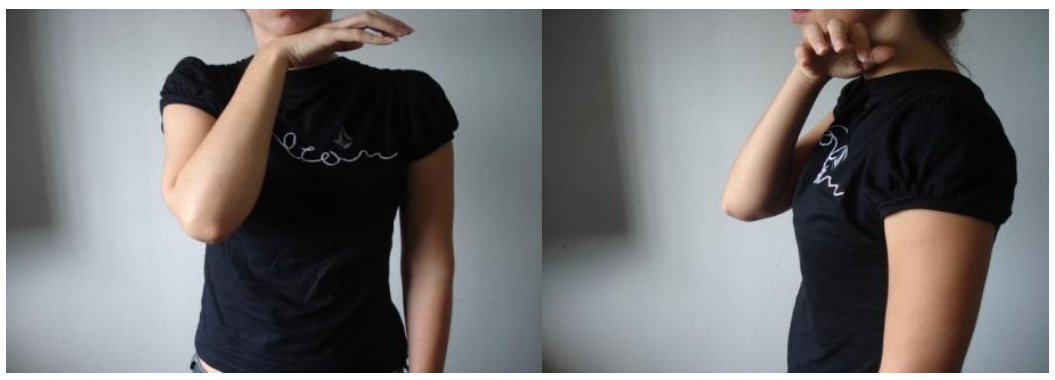

Figura 12: sinal de leão segundo o "Dicionário enciclopédico ilustrado trilíngue da Língua de Sinais Brasileira" (2001).

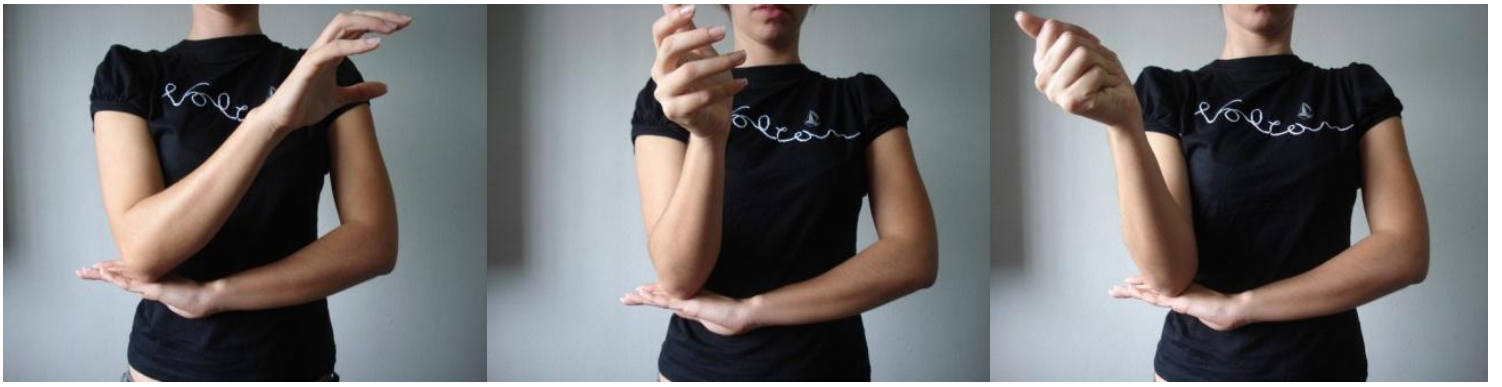

Figura 13: variante do sinal de leão.

Na figura 12, o sinal é articulado no queixo, enquanto na figura 13 o ponto de articulação é na mão passiva (mão esquerda).

Pesquisas linguísticas sobre o português brasileiro chegaram à conclusão que o nível de escolaridade é o principal fator a ser levado em conta na hora de classificar um falante e sua variedade. O rótulo falante culto é aplicado ao indivíduo que tem curso superior completo (BAGNO, 2003). Os dados encontrados nesta pesquisa são compatíveis com os realizados com o português, citado na literatura, na medida em que ocorreram mais variações na escolaridade de $1^{\circ}$ ao $5^{\circ}$ ano (CM - 57,52\%; M - 50,75\%; PA - 46,62\%) e uma menor 
incidência com os sujeitos do ensino superior (CM - 46,93\%; M - 37,55\%; PA - 37,14\%), em todos os parâmetros pesquisados.

Essa diferença também foi encontrada em uma população ouvinte (CALVET, 2002), contudo outro aspecto da variação linguística importante deve ser observado, que é a variação referente ao fator sexo, pois é notável a diferença do comportamento social - e, por conseguinte, linguístico - existente entre homens e mulheres. Como frequentemente é observada nas línguas faladas, a mulher é mais inclinada a adotar a língua legítima (ou a pronúncia legítima), elas são voltadas à docilidade para com os usos dominantes e pela divisão de trabalho entre os sexos, que as especializa no campo do consumo, pela lógica do casamento, elas demonstram que estão dispostas a aceitar, especialmente na escola, as novas exigências do mercado de bens simbólicos (CALVET, 2002).

Os resultados apontam que as mulheres apresentam maior incidência de variação na realização dos sinais (CM - 54,05\%; M - 43,63\%; PA - 42,85\%). A diferença no comportamento linguístico dos homens e mulheres deve-se ao fato de os homens estarem mais expostos a uma "multidão" de pessoas e por isso usarem mais as variantes "grosseiras", em oposição às mulheres que permaneciam isoladas, além do fato de serem mais receptivas à linguagem padrão do que os homens (CHAMBERS, 1995).

Numa estratificação sociolinguística estável, os homens usam mais as formas não padrão do que as mulheres; na maioria dos processos de mudança linguística, são as mulheres que inovam, usando formas não padrão (LABOV, 2008[1972]).

Nas línguas faladas, o sexo masculino não sente a necessidade de questionar seu modo de falar, pois consideram sua maneira de falar como forma legítima da língua (CALVET, 2002). Na Libras, como foi demonstrado nesta pesquisa, foram observadas menos variações em comparação ao sexo feminino, em todos os parâmetros analisados (CM - 52,74\%; M 41,94\%; PA - 39,64\%).

Com relação à faixa etária, a pesquisa mostrou que os sujeitos entre 33 e 41 anos apresentaram uma quantidade maior de variações dos sinais. O atual cenário educacional é 
responsável por essa realidade na cultura surda. No passado, o isolamento era grande. Os sinais eram passados de geração a geração.

Foi observado que na Libras utilizada em Maceió, assim como na Nova Zelândia (MCKEE; MCKEE, 2006) ocorreram variações linguísticas no léxico da Língua de Sinais, decorrentes do modelo educacional, visto que grupos de sujeitos surdos usuários desta língua apresentaram diferenças no seu uso comparado a um grupo mais jovem. As variações ocorreram em maior proporção na faixa etária mais velha, pois os sujeitos não vivenciaram um período educacional em que a língua de sinais foi introduzida nas escolas e a comunidade surda não passava pelo processo de mudança de língua.

A Libras, como todas as línguas, apresenta paramorfismo, quando diferentes sinais têm significados similares ou equivalentes; ou diferentes formas e estruturas, ou seja, expressões próprias de uma cultura, ou mesmo particular de uma região, que são específicas de uma língua influenciadas por questões sociais, culturais e econômicas, não podendo ser decodificadas literalmente, pois são culturais.

Em decorrência de motivos sócio-culturais e históricos, algumas variedades são consideradas como sendo as melhores, e essa se denomina língua padrão advinda do poder econômico, social e político; as outras variedades são formas linguísticas consideradas pobres, e vistas, é claro, de maneira pejorativa. Essas diferenças são estigmatizadas e, portanto, recebem a maior carga de preconceito e rejeição por parte do conhecedor do português padrão. Diante disso, a língua não pode ser considerada apenas pelo valor ideológico, mas como resultado de fatos sociais, passíveis de serem analisados e compreendidos por critérios linguísticos modernos (BAGNO, 2003).

\section{Considerações Finais}

Esta pesquisa verificou a ocorrência de variações linguísticas na língua de sinais utilizada em uma comunidade de sinalizadores (usuários da Língua Brasileira de Sinais) surdos, a partir da correlação de fatores sociais, tais como: sexo, idade e escolaridade. Foi observado que a variação linguística está presente na Libras, assim como em outras línguas consideradas

Revista Leitura v. 1, no 58 - Maceió - Jan./Jun. 2017 - ISSN 2317-9945

Línguas de Sinais: abordagens teóricas e aplicadas, p. 47-67 
naturais. Nos dados coletados, ocorreu um maior número de variações linguísticas com os sinalizadores que possuíam escolaridade de $1^{\circ}$ ao $5^{\circ}$ ano, idade entre 33 a 41 anos e do sexo feminino, nos três parâmetros de análise: configuração manual, movimento e ponto de articulação.

Assim, fica evidente que o uso particular que cada sinalizador faz da língua pode variar, segundo seu nível de instrução, idade, região e, principalmente, a situação em que acontece o uso da língua, ou seja, os indivíduos que utilizam a mesma língua não a usam exatamente igual, e isso acontece porque o homem, afirmando o que ora foi escrito, pertence a diversos grupos sociais e, consequentemente, é levado a utilizar a língua de diversas maneiras.

Esta descrição sucinta da variação linguística na Libras não é suficiente para conhecê-la na sua estrutura como um todo e, muito menos, em suas especificidades enquanto língua de uma comunidade. No entanto, parece ser um primeiro passo para que saibamos que a Libras é uma língua natural com toda complexidade dos sistemas linguísticos que servem à comunicação, socialização e ao suporte do pensamento de muitos grupos sociais.

Durante muito tempo as línguas de sinais foram consideradas apenas como gestos, incapazes de expressar conceitos abstratos. Até hoje, ainda há muito preconceito e desconhecimento sobre elas, principalmente, porque a pesquisa nesta área ainda está sendo iniciada e há poucos profissionais pesquisando e difundindo seu trabalho, não só para a comunidade acadêmica, como para a comunidade local em geral, visto que mesmo a despeito de mais de um século de proibição de seu uso nas escolas de surdos, preconceito e marginalização por parte da sociedade como um todo, as línguas de sinais resistiram, demonstrando a necessidade essencial de sua utilização entre as pessoas surdas.

\section{Referências}

BAGNO, M. (Org). A norma oculta: língua, poder na sociedade brasileira. São Paulo: Parábola, 2003.

FERREIRA BRITO, L. Por uma gramática de língua de sinais. Rio de Janeiro: Tempo Brasileiro, 1995. 
CALVET, L. Sociolingüística: uma introdução crítica. São Paulo: Parábola, 2002.

CAPOVILLA, F. C.; RAPHAEL, W. D. Dicionário enciclopédico ilustrado trilíngue da Língua de Sinais Brasileira. 2. ed. Vol. I. São Paulo: Editora da Universidade de São Paulo, 2001.

Dicionário enciclopédico ilustrado trilíngue da Língua de Sinais Brasileira. 2. ed. Vol. II. São Paulo: Editora da Universidade de São Paulo, 2001.

CHAMBERS, J. K. Sociolinguistic theory. Oxford: Blackwell, 1995.

DIZEU, L. C. T. de B. Variações Lingüísticas na escrita do surdo pelo contato da Língua Brasileira de Sinais e o português. Dissertação (Mestrado em Letras e Linguística). Maceió: Universidade Federal de Alagoas, 2006.

GOMES, C. A.; SOUZA, C. N. R. de. Variáveis fonológicas. In: Mollica, M. C. (Org.). Introdução à Sociolingüística Variacionista. 2 ed. Rio de Janeiro: UERJ, 2004, p. 73-80.

HOITING, N.; SLOBIN, D. I. Transcription as a tool for understanding: the Berkeley Transcription System for sign language research (BTS). In: G. Morgan \& B (Org.). Directions in sign language acquisition. Amsterdam/Philadelphia: John Benjamim, 2002, p. 55-75.

HORA, D. Teoria da variação: trajetória de uma proposta. In:

Estudos Sociolingüísticos: perfil de uma comunidade. João Pessoa: Pallotti, 2004, p. 13-28.

JOKINEN, M. Alguns pontos de vista sobre a educação dos surdos nos países nórdicos. In: SKLIAR, C. (Org). Atualidade da educação bilíngüe para surdos. Porto Alegre: Mediação, 1999, p. 105-128.

LABOV, W. Sociolinguistque. Paris: Les Éditions de Minuit, 1972.

MCKEE, D.; MCKEE R. Investigating sociolinguistic variation in New Zealand Sign Language. In: Quadros, R. M. Anais do IX Congresso Internacional de Aspectos Teóricos das Pesquisas nas Línguas de Sinais. Florianópolis: Lagoa Editora, 2006, p. 127-128.

MINISTÉRIO DA EDUCAÇÃO. Lei no . 10.436, de 24 de abril de 2002. Disponível em: <http://www.planalto.gov.br/ccivil_03/leis/2002/110436.htm>. Acesso em: 24 de Abr. de 2017.

MOLliCA, M. C. Sociolingüística: conceituação e delimitação. In: Mollica, M. C. (Org.). Introdução à Sociolingüística Variacionista. 2. Ed. Rio de Janeiro: UERJ, 1994, p. 13-15.

MOURA, M. C. et al. História e educação: o surdo, a oralidade e o uso de sinais. In: FILHO, O. L. Tratado de Fonoaudiologia. São Paulo: Roca, 1997, p. 327-358. 
PEREIRA, M. C. da C. A Língua de Sinais na Educação de Surdos. In: LACERDA, C B. F. de; NAKAMURA, H.; LIMA, M. C. (Org.). Fonoaudiologia: surdez e abordagem bilíngue. São Paulo: Plexus, 2000, p. 13-20.

Educação de surdos: a aquisição da linguagem. Porto Alegre: Artes Médicas, 1997.

QUADROS, R. M. de; KARNOPP, L. B. Língua de Sinais Brasileira: estudos linguísticos. Porto Alegre: Artmed, 2004.

STOKOE, W. Sign Language structure. Silver Springs, Maryland: Linstok Press, 1960.

\begin{abstract}
This research aimed to describe the occurrence of linguistic variation in Sign Language used in Maceió/ AL. To develop this study, we used the assumptions of variationist sociolinguistics (LABOV, 2008 [1972]) whose main objective is demonstrating that the apparent linguistic chaos can be systematized and described the linguistic variation may be occurring through the influence linguistic and social factors. The corpus of this research was made by recording the signals of 50 figures made by 23 informants stratified according to the following extralinguistic factors: sex, age and education. According to the results of the corpus, it can be said that the Brazilian Sign Language used in Maceió/AL presents variations conditioned by extralinguistic and internal factors for your system, therefore, the groups from 1 st to 4 th grade, women between 3341 years old, showed more variation in the parameters analyzed (manual configuration, move and pivotpoint).
\end{abstract}

Keywords: Sign language. Sociolinguistics. Variation

Revista Leitura v. 1, no 58 - Maceió - Jan./Jun. 2017 - ISSN 2317-9945

Línguas de Sinais: abordagens teóricas e aplicadas, p. 47-67 
Anexo 1 - Itens lexicais de cinco categorias semânticas.

\begin{tabular}{|c|c|c|c|}
\hline $\begin{array}{c}\text { NÚMERO } \\
\text { DE } \\
\text { SINAIS }\end{array}$ & SINAL & $\begin{array}{c}\text { NÚMERO } \\
\text { DE } \\
\text { SINAIS }\end{array}$ & SINAL \\
\hline 1. & CARNE & 26. & AVIÃO \\
\hline 2. & QUEIJO & 27. & CARROÇA \\
\hline 3. & MACARRÃO & 28. & TREM \\
\hline 4. & MAÇ $\tilde{A}$ & 29 & HELICOPTERO \\
\hline 5. & MORANGO & 30. & ONIBUS \\
\hline 6. & CAJÚ & 31. & BOLSA \\
\hline 7. & ABACAXI & 32. & RELOGIO \\
\hline 8 . & PÃO & 33. & VESTIDO \\
\hline 9 . & CHOCOLATE & 34. & GRAVATA \\
\hline 10. & PIPOCA & 35. & SAPATO \\
\hline 11. & MACACO & 36. & CALCINHA \\
\hline 12. & BORBOLETA & 37. & CAMISA \\
\hline 13. & BOI & 38. & CALÇA \\
\hline 14. & CAVALO & 39. & SANDALIA \\
\hline 15. & CACHORRO & 40. & CHAPEU \\
\hline 16. & TARTARUGA & 41. & MARROM \\
\hline 17. & SAPO & 42. & AZUL CLARO \\
\hline 18. & GATO & 43. & AZUL ESCURO \\
\hline 19. & LEÃO & 44. & LARANJA \\
\hline 20. & GALINHA & 45. & AMARELO \\
\hline 21. & BICICLETA & 46. & CINZA \\
\hline 22. & MOTO & 47. & VERMELHO \\
\hline 23. & CARRO & 48. & VERDE \\
\hline 24. & CAMINHÃO & 49. & PRETO \\
\hline 25. & NAVIO & 50. & ROSA \\
\hline
\end{tabular}


Variação linguística na Lingua Brasileira de Sinais utilizada em Maceió/Alagoas Priscila Rufino da Silva, Liliane Correia Toscano de Brito Dizen

\section{Anexo 2 - Movimentos da Libras (FERREIRA BRITO, 1990).}

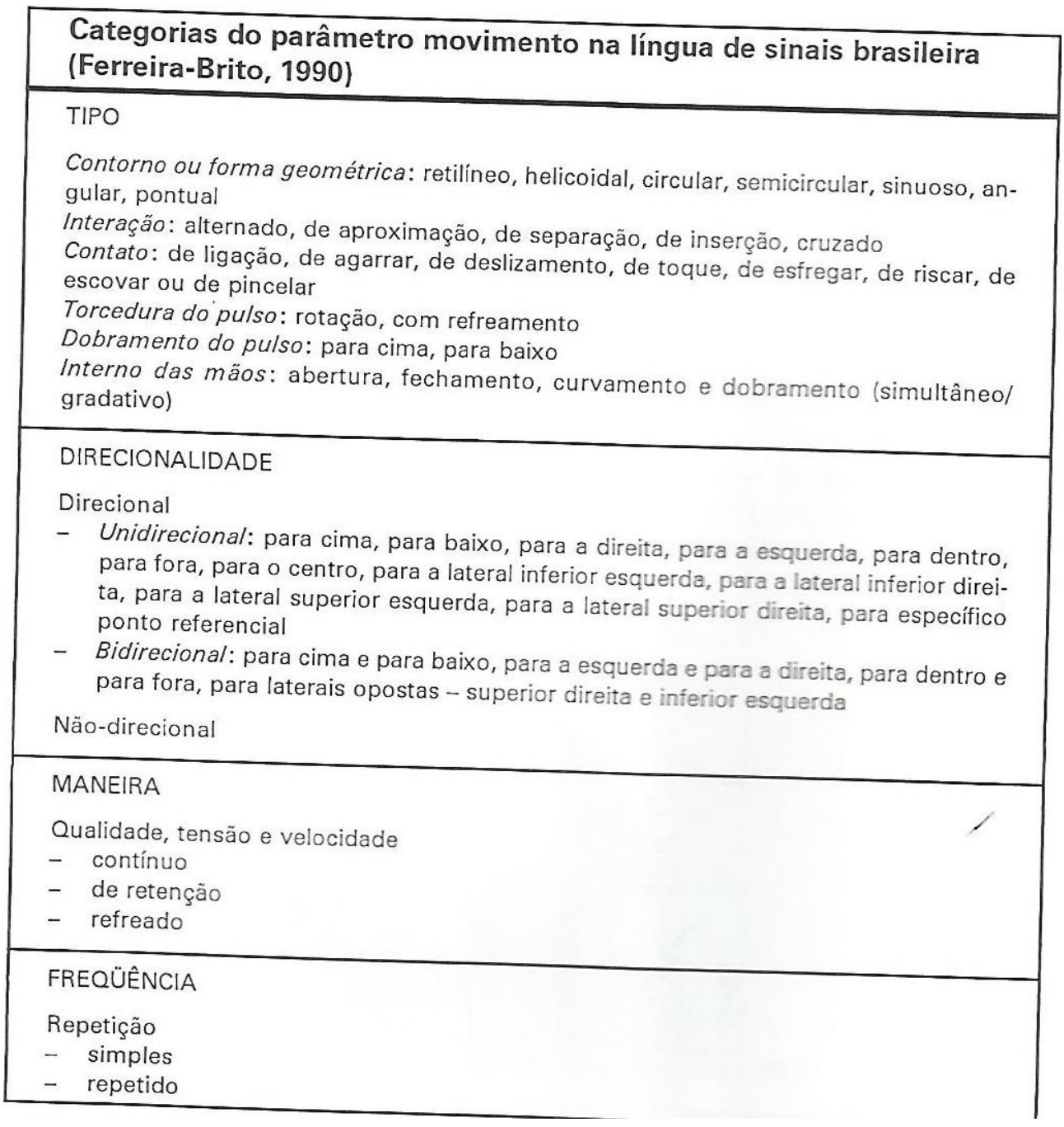

Revista Leitura v. 1, no 58 - Maceió - Jan./Jun. 2017 - ISSN 2317-9945

Línguas de Sinais: abordagens teóricas e aplicadas, p. 47-67 